\title{
Determinants of Beneficiary Effects of Physical Activity among Adult Population in US
}

\author{
Erfan Ayubi ${ }^{1,2}$, Salman Khazaei ${ }^{3}$, Kamyar Mansori $^{4,5}$, Saeid Safiri ${ }^{6}$, Mohadeseh \\ Sani $^{7}$, Alireza Mosavi Jarrahi ${ }^{8,9,10}$
}

\begin{abstract}
${ }^{1}$ Department of Epidemiology, School of Public Health, Shahid Beheshti University of Medical Sciences, Tehran, Iran. ${ }^{2}$ Department of Epidemiology and Biostatistics, School of Public Health, Tehran University of Medical Sciences, Tehran, Iran. ${ }^{3}$ Department of Epidemiology, School of Public Health, Hamadan University of Medical Sciences, Tehran, Iran. ${ }^{4}$ Social Development and Health Promotion Research Center, Gonabad University of Medical Sciences, Gonabad, Iran. ${ }^{5}$ Department of Epidemiology, School of Public Health, Iran University of Medical, Tehran, Iran. ${ }^{6}$ Managerial Epidemiology Research Center, Department of Public Health, School of Nursing and Midwifery, Maragheh University of Medical Sciences, Maragheh, Iran. ${ }^{7}$ Department of Public Health, School of Public Health, Zabol University of Medical Sciences, Zabol, Iran. ${ }^{8}$ The Health Metrics Research Center, Department of Social Medicine, Medical School, Shahid Beheshti University of Medical Sciences, Tehran, Iran. ${ }^{9}$ The Cancer Research Center of the Cancer Institute, Tehran University of Medical Sciences, Tehran, Iran. ${ }^{10}$ Visiting Prof. School of Health Sciences, Simon Fraser University, BC, Canada.
\end{abstract}

\begin{abstract}
Physical activity, if reaches to a beneficiary level, positively affect almost all the chronic diseases. The aim of this study was to determine the socio-demographic and anthropometric determinants of beneficiary effects of different domains of physical activity. Physical activity data from the National Health and Nutrition Examination Survey 2005-2006 were utilized. A cut off point of 7.5 MET-hour/week was used a level in which beneficiary effect of physical activity starts. Logistic regression model were used to evaluate the magnitude and the determinants of beneficiary effects for each domains of physical activity. The median of physical activity was mainly similar for leisure time, home and garden, and total physical activity across different categories of socio-demographic factors but not with Transportation domain. The transportation contributed up to $60 \%$ for age group $35-54$ years, $35 \%$ for age group 55 to 64 years. Male enjoyed close to $37 \%$ more in achieving health benefit compared to female (the OR was 0.63 with $95 \% \mathrm{CI}$ of $0.58,0.69)$. Others factors played important role in different dominos of physical activity in achieving health benefits. Our findings indicated that achieving beneficiary effect of physical activity is highly depended on socio-demographic factors
\end{abstract}

Keywrds: Home and garden physical activity- transportation physical activity- leisure time physical activity

Asian Pac J Cancer Care, 2 (1), 15-20

\section{Introduction}

The epidemiologic transition has led to changes in the prevalence of infectious diseases and an increase in diseases that are related to lifestyle [1]. Regular physical activity is associated with decreasing the risk of coronary heart disease [2], hypertension [3], cerebral stroke [4], type 2 diabetes [5-6], some cancers [7-8], osteoporosis [9], obesity [10-11], and total mortality [12]. It is well documented that the prevalence of physical inactivity
Submission Date: 11/18/2016 Acceptance Date: 01/25/2017

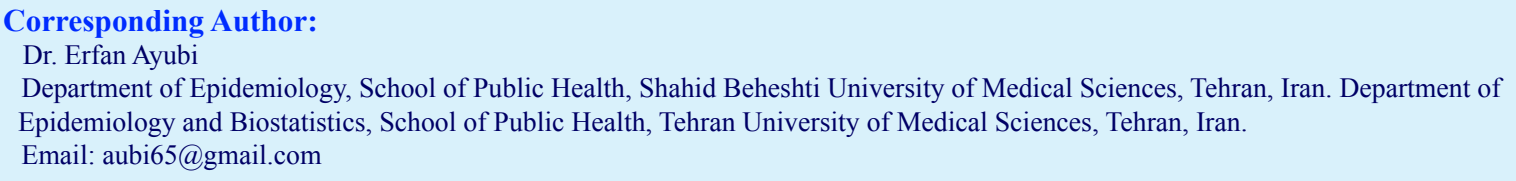


nationwide surveys in many developed countries showing a diverse result both from stand point of total physical activities (includes all domains of activity) and domain specific physical activities. In Europe, the European Activity Surveillance System (EUPASS) project has reported the highest median total physical activity scores of 84.5 MET/hour/ week for Germany and lowest score of 19.6 MET-hour/week for Italy [15]. The distribution of physical activity throughout different domains indicates higher health benefit in the domains of leisure-time and transport compared with home and garden [12]. A systematic review and dose-response meta-analysis of cohort studies demonstrated lower mortality for leisure time activity compare with daily and home and garden [16]. This differential impact of different domain in favoring health outcome has been reported in breast and other hormone related cancers [17], cardiovascular especially hypertension and stroke, colon, prostate, lung, and mental disorder. In the light of the differential health benefit of different domains of physical activity, this study utilized the NHANES 2005-2006 data to evaluate how socio- demographic and anthropometric factors are influencing the beneficial level of different domains of physical activity.

\section{Materials and Methods}

\section{Study population}

The National Health and Nutrition Examination Survey 2005-2006 is a representative sample of non-institutionalized population in the United States. It uses a complex multistage cluster design to estimate the prevalence of factors related to chronic diseases. The survey includes household interviews and examinations conducted in mobile examination centers. This study utilized data generated in the 2005-06 survey. Five thousand one hundred eighty two participants that completed the physical activity questionnaire were included into this study.

\section{Measurements}

A detailed methodology of the survey has already been reported [18]. In brief; the frequency, duration, and intensity of physical activity for the three domains of home and garden, transportation, leisure time, and total physical activities were measured by a questionnaire administered by trained interviewers [19]. The questionnaire measured the daily activities of sampled population for last thirty days. Physical activity were defined in four domains; home and garden (activities that include any tasks in home or yard for at least 10 minutes that required moderate or greater physical effort including tasks that caused light sweating or a slight to moderate increase in one' heart rate or breathing such as raking leaves, mowing the lawn or heavy cleaning), transportation (activities that includes walk or bicycle as part of getting to and from work, or school, or to do errands), Leisure time (activities that include moderate or vigorous activity over past 30 days such as brisk walking, bicycling for pleasure, golf, dancing and etc...), and total phial activities (includes all activities performed in all domains of physical activities. Physical activity related to earning income jobs were not available and did not included into our study. Physical activities were expressed as Metabolic Energy Equivalent b time (MET).

A beneficiary health effect was judged based on the recommendation from the American College of Sport Medicine and the American Heart Association which indicate a minimum of activity 450 Metabolic minutes/week or 7.5 metabolic equivalent hours/week (approximately 2 hours and 30 minutes of moderate activity or 1 hour and 15 minutes of rigorous activity) to receive an adequate amount of health benefits [20].

\section{The studied factors}

The socio-demographic factors included age, race, marital status, family size, education level, household income, citizenship status and anthropometric factors were height and weight, expressed as body mass index in the analysis.

\section{Statistical Analysis}

Two sets of statistical analysis were preformed, the first included a univariate analysis describing the frequency and comparing the median score of the physical activity across different categories of each factor using Mann-Whitney U Test and Kruskal-Wallis test for each domain of physical activity. The second line of analysis included a multivariate analysis using logistic regression model. For the multivariate model, subjects were grouped based on their physical activity as those who met a metabolic equivalents/minutes/week of 450 or 7.5 metabolic equivalent of hours a week and those who did not met (weekly activities of less than 450 MET-hour/week were considered as null). The determinants of beneficial achievement were evaluated for the domains of home and garden, transportation, leisure time, and total physical activities. Stata SE (ver 11.0) for Windows was used for data analyses and p-values 0.05 were considered as a statistically significant level.

\section{Results}

The crude median physical activity for the entire sampled population was $11.37(95 \% \mathrm{CI}, 10.99-11.75)$ for total physical activity and $6.75(95 \% \mathrm{CI}, 5.84-7.65)$ for home and garden, 6( 95\% CI, 5.20-6.79) for transportation, and $6.12(95 \% \mathrm{CI}, 5.71-6.5) 3$ for leisure time.

The median score of physical activity was almost similar for leisure time across different age group (the median was 6.25 for age group 15-34, 6.00 for 35-54, and 6.75 for 55-64 with no statistically significant differences, $p$-value $=0.23$ ), home and garden (the median was 6.75 for age group 15-34, 5.62 for 35-54, and 6.75 for $>55$ with a statistically significant differences, $p$-value $<0.01$ ) but the scores were not similar in the transportation domain (the median was 6.00 for age group 15-34, 7.00 for 35-54, and 5.00 for $>55$ with a statistically significant differences, $\mathrm{p}$-value $<0.01)$. No major differences were seen between sexes in almost all domains (for male the 
Table 1. Descriptive Measures of Different Domains of Physical Activity for Different Socio-Demographic and Anthropometric Factors

\begin{tabular}{|c|c|c|c|c|c|}
\hline Variables & $\mathrm{N}$ & Transportation & Home and garden & Leisure time & Total physical activity \\
\hline \multicolumn{6}{|l|}{ Age } \\
\hline $15-34$ & 2,887 & 6 & 6.75 & 6.25 & 11.72 \\
\hline $35-54$ & 1,558 & 7.5 & 5.62 & 6 & 10.87 \\
\hline $55-64$ & 633 & 5 & 6.75 & 6.75 & 11.81 \\
\hline $\mathrm{p}$-value $\dagger$ & & $<0.01$ & $<0.01$ & 0.23 & $<0.01$ \\
\hline \multicolumn{6}{|l|}{ Sex } \\
\hline Male & 2,460 & 6 & 6.75 & 6 & 11.25 \\
\hline Female & 2,722 & 6 & 6.75 & 6.25 & 11.81 \\
\hline p-valuet & & $<0.01$ & $<0.01$ & $<0.01$ & $<0.01$ \\
\hline \multicolumn{6}{|l|}{ Ethnic } \\
\hline White & 2,054 & 6.66 & 6.75 & 6.5 & 11.84 \\
\hline Black & 1,384 & 6 & 6.45 & 6.12 & 11.25 \\
\hline Other & 1,744 & 6.25 & 6.1 & 6 & 11 \\
\hline $\mathrm{p}$-value $\dagger$ & & $<0.001$ & $<0.001$ & $<0.001$ & $<0.001$ \\
\hline \multicolumn{6}{|l|}{ Marital status } \\
\hline Marital & 2,052 & 6 & 5.62 & 6.12 & 11.25 \\
\hline Other & 3,125 & 6.66 & 7.5 & 6.25 & 11.81 \\
\hline p-value & & $<0.01$ & 0.25 & $<0.01$ & 0.02 \\
\hline \multicolumn{6}{|l|}{ Education level } \\
\hline >Diploma & 1,769 & 6.15 & 6.75 & 5.9 & 11.25 \\
\hline Diploma $<$ & 1,953 & 6 & 5.9 & 6.12 & 12.1 \\
\hline p-value & & 0.1 & 0.54 & $<0.001$ & $<0.001$ \\
\hline \multicolumn{6}{|l|}{ Household income } \\
\hline$>2500 \$$ & 1,340 & 6 & 7.31 & 6 & 12 \\
\hline $25,000-50,000 \$$ & 1,593 & 7.5 & 6.75 & 6.5 & 11.68 \\
\hline $50,000 \$<$ & 2,174 & 6.3 & 5.62 & 6.25 & 11.17 \\
\hline $\mathrm{p}$-value $\dagger$ & & $<0.001$ & $<0.001$ & $<0.001$ & $<0.001$ \\
\hline \multicolumn{6}{|l|}{ Family size } \\
\hline$<3$ people & 2,829 & 6 & 6.75 & 5.8 & 11.25 \\
\hline 3 people $<$ & 2,353 & 6.66 & 6.4 & 6.43 & 11.37 \\
\hline p-valuet & & $<0.001$ & $<0.001$ & $<0.001$ & $<0.001$ \\
\hline \multicolumn{6}{|l|}{ BMI } \\
\hline$<20$ & 1,253 & 6 & 6.75 & 6 & 11.37 \\
\hline $20-24.9$ & 1,171 & 6.66 & 5.62 & 6.25 & 11.25 \\
\hline $25-29.9$ & 1,044 & 5.33 & 6.55 & 6.5 & 12.25 \\
\hline $30<$ & 1,034 & 6.66 & 7.31 & 6.25 & 11.62 \\
\hline p-value $\dagger$ & & $<0.001$ & $<0.001$ & $<0.001$ & $<0.001$ \\
\hline
\end{tabular}

$\dagger$ Kruskal-Wallis ANOVA, two sided P.value $<0.05 ; \ddagger$ Mann-Whitney U Test, two sided P.value $<0.05$

median was 6.00 for transportation, 6.75 for home and garden, and 6.00 for leisure time, and 11.25 for total physical activities. These figures were 6.00, 6.75, 6.25, and 11.81 for female, respectively).

Certain category of house hold income or BMI had lower median score of physical activities compared with other corresponding categories (people in the categories of 25,000 to 50,000 yearly income scored 7.5 MET-hour/week, and obese people and people with BMI category of 20-24.9 scored very low, MET-hour/week).
Table 1 presents the details for all the studied variables. The multivariate analysis revealed while no statistically differences in achieving health benefit among different categories of age group in the domain of total physical activity (odds ratio, OR of 1.0 with $95 \% \mathrm{CI}$ of $0.92-1.09$, and 1.03 with $95 \%$ CI of 0.92-1.14) however, transportation contributed up to $60 \%$ for age group $35-54$ years, $35 \%$ for age group 55 to 64 years towards a beneficiary health effects when these categories were compared with age group less than 35). There was no major differences 
Table 2. The Odds Ratio and Their 95\% Confidence Intervals for Factors Associated with a Beneficiary Effect in All Studied Domains

\begin{tabular}{|c|c|c|c|c|c|}
\hline \multirow[t]{2}{*}{ Independent variable } & \multicolumn{3}{|c|}{ Dependent variable $\quad(\mathrm{OR} \uparrow, 95 \% \mathrm{CI})$} & \multirow[b]{2}{*}{ Leisure time } & \multirow[b]{2}{*}{ Total physical activity } \\
\hline & $\mathrm{N}$ & Transportation & Home and garden & & \\
\hline \multicolumn{6}{|l|}{ Age } \\
\hline $15-34$ & 2,887 & - & - & - & - \\
\hline $35-54$ & 1,558 & $(1.60,1.45-1.78) \S$ & $(0.93,0.87-1.01)$ & $(1.03,0.97-1.10)$ & $(1,0.92-1.09)$ \\
\hline $55-64$ & 633 & $(1.35,1.18-1.54) \S$ & $(1.46,1.31-1.62) \S$ & $(1.06,0.97-1.15)$ & $(1.03,0.92-1.14)$ \\
\hline \multicolumn{6}{|l|}{$\operatorname{sex}$} \\
\hline Male & 2,460 & - & - & - & - \\
\hline Female & 2,722 & $(0.63,0.58-0.69) \S$ & $(1.03,0.96-1.10)$ & $(0.94,0.89-1.01)$ & $(1.05,0.98-1.13)$ \\
\hline \multicolumn{6}{|l|}{ Ethnic } \\
\hline White & 2,054 & - & - & - & - \\
\hline Black & 1,384 & $(0.48,0.42-0.54) \S$ & $(0.73,0.67-0.80) \S$ & $(0.92,0.86-0.98)$ & $(0.88,0.80-0.96) \S$ \\
\hline Other & 1,744 & $(0.88,0.80-0.98) \dagger$ & $(0.87,0.81-0.94) \S$ & $(0.92,0.86-0.99) \$$ & $(0.89,0.81-0.97) \S$ \\
\hline \multicolumn{6}{|l|}{ Marital status } \\
\hline Marital & 2,052 & - & - & - & - \\
\hline Other & 3,125 & $(1.14,1.04-1.25) \S$ & $(1.33,1.28-1.49) \S$ & $(0.93,0.87-0.98) \ddagger$ & $(1.09,1.02-1.18) \ddagger$ \\
\hline \multicolumn{6}{|l|}{ Education level } \\
\hline >Diploma & 1,769 & - & - & - & - \\
\hline Diploma $<$ & 1,953 & $(1.16,1.05-1.27) \S$ & $(0.93,0.87-1.01)$ & $(0.95,0.90-1.02)$ & $(0.92,0.86-1.01)$ \\
\hline \multicolumn{6}{|l|}{ Household income } \\
\hline$>2,500 \$$ & 1,340 & - & - & - & - \\
\hline $25,000-50,000 \$$ & 1,593 & $(0.94,0.83-1.06)$ & $(1.53,1.40-1.67) \S$ & $(0.97,0.89-1.05)$ & $(0.92,0.83-1.02)$ \\
\hline $50,000 \$<$ & 2,174 & $(1.26,0.80-0.98) \S$ & $(2.28,2.08-2.50) \S$ & $(0.84,0.78-0.91) \S$ & $(0.75,0.68-0.83) \S$ \\
\hline \multicolumn{6}{|l|}{ Family size } \\
\hline$<3$ people & 2,829 & - & - & - & - \\
\hline 3 people $<$ & 2,353 & $(1.37,1.24-1.51) \S$ & $(1.08,1.01-1.16) \ddagger$ & $(0.94,0.88-1.01)$ & $(1,0.92-1.08)$ \\
\hline \multicolumn{6}{|l|}{ BMI } \\
\hline$<20$ & 1,253 & - & - & - & - \\
\hline $20-24.9$ & 1,171 & $(1.26,1.11-1.42) \S$ & $(0.77,0.70-0.84) \S$ & $(0.98,0.91-1.07)$ & $(0.87,0.79-0.96) \S$ \\
\hline $25-29.9$ & 1,044 & $(0.84,0.74-0.96) \ddagger$ & $(0.82,0.75-0.91) \S$ & $(1.05,0.97-1.14)$ & $(0.96,0.87-1.07)$ \\
\hline $30<$ & 1,034 & $(1.33,1.18-1.49) \S$ & $(1.05,0.95-1.15)$ & $(0.99,0.91-1.07)$ & $(0.87,0.79-0.96) \S$ \\
\hline
\end{tabular}

†Odds Ratio; †Two sided P.value $<0.05 ; \S$ Two sided P.value $<0.01$

between male and female in the domains of leisure time, and home and garden, and total physical activity but in transportation domain, male enjoyed close to $37 \%$ more in achieving health benefit compared to female (the OR was 0.63 with $95 \%$ CI of $0.58,0.69$ ). Race played an important role in achieving benefit from transportation and home and garden domain compared to total physical or leisure time activity domains. Education did not contribute to achieving health benefit from any domain of activities, though a weak association (Odds ratio $=1.16$ , 95\% CI of $1.05,1.27$ ) was observed favoring higher education in achieving health benefit from transportation compared to lower level of education. There was strong association between income and achieving health benefit from transportation, and home and garden domain (in the transportation domain, the OR was 0.94 with $95 \%$ CI 0.83 , 1.06 for category with yearly income of 25,000 to 50,000 and 1.26 with $95 \%$ CI $1.12,1.41$ for category with income more than 500,000. These figures were 1.53 with $95 \% \mathrm{CI}$ of $1.40,1.68$ and 2.28 with $95 \%$ CI of $2.07,2.50$ for the domain of home and garden respectively). Income was negatively associated with beneficiary effect from leisure time and total physical activity domain (Table 2). Except for transportation domain that was positively associated with BMI in achieving health benefit, other domains did not. Table 2 present the details of the logistic regression for all the studied factors in the studied domains of physical activity.

\section{Discussion}

Our study described the three major domains of physical activity and their contribution to achieving health benefit from the activities that people are routinely subject to. In addition we demonstrated the determinant of achieving health benefit from physical activity and how soci-demoraphic factors are affecting the beneficiary outcome of physical activity in each domain of physical 
activity. While there are lots of data on the nature of physical activity and its determinant, no study has addressed the determinate of beneficiary effect of physical activity. In a study by Jurakic [21] showed that men are more active than women and the fact that different age groups have different physical activity profile in line with our finding but when it comes to beneficiary effect, middle age group benefited more than younger and this was mainly in the domain of transportation. Contrary to our result, Zanchetta [22] and Bicalho [23] reported that men are less active than women that woman under the age of 30 and older than 50 had the highest and lowest levels of physical activity respectively. Discrepancy between our result with others is due the fact the different population are compared and such discrepancy is legitimate as the population are different.

Our data indicated that for the entire soci-demographic factors transportation domain had a great impact on discrimination among different categories for each factor indicating a potent public health avenue in promoting physical activity. It has been reported that transportation activity tend to be stable during one's life so that younger age means of transportation is correlated with adulthood means of transportation [24] an indication of how transportation can be utilized as a means to promote physical activity at broader community level.

We showed that body mass index (BMI) has a weak association with total physical activity and transportation domain. The effect of higher BMI was negatively associated with achieving health benefit this could be based on the fact that person of higher BMI are less physically active and the fact that higher BMI is in fact a risk factor for less physical activities [25].

Godin [26] showed that BMI had both a direct and an indirect effect on physical activity in leisure time domain; he suggested that people with high BMI are negatively associated with physical activity during leisure time. However, a study by Costa Dias-da [27] reported that there is a negative association between leisure time activity and BMI, meaning people who are overweight actually have more mobility. Another study showed that people who are not overweight are more active and benefited more from transportation compared to other domain [28]. The effect of BMI on physical activity is very complex however as the prevalence overweight and obesity increasing specially in younger age [29], the BMI will play a major modifying factor in promoting higher physical activity and beneficiary effect of physical activities.

A positive association between education level and achieving health benefit in transportation domain was observed but not with leisure time activity. This is contrary to others' finding that indicates educated people tend to live healthier life and be more physically active especially in the leisure time domain. This fact has been attributed to a better understanding of the benefits of physical activity plus has access to a more resources among the more educated people. A study by Monteiro et al [28] and colleagues reported that there is a linear relationship between leisure time physical activity and low education in man but not in women. For women there is a positive association between leisure time physical activity with both education level and household income. Jurakic et al [21] showed that education and household income levels are negatively associated with leisure time activities, which suggests that people with low education and income will participate less in leisure time activities, due to the lack of time and financial resources. Variation and lack of consistency between our study and others may be due to the fact that we evaluated the beneficiary effect and others just correlate the different level with different scores of physical activity. In our study, married people enjoyed beneficiary effect in all domains except for leisure time similar finding has been reported by other authors [30,31].

In our study, physical activity was measure by international physical activity questionnaire, a validated questionnaire frequently being used by different study group making our result comparable to others' result in measurement consistency. Another advantage of our study is use of data from a fairly representative sample increasing our external validity of the finding especially among the broader US population.

Our study has several limitations that should be considered. The measurement of physical activity in different domains was based on self-reported material. This may lead to over reporting of physical activity by specific groups or different categories of sociodemographic factors (i.e. senior citizens). Our study did not include physical activity in workplace. It has been reported that work place physical activity can have great effect on achieving health benefit [32] One of the problems that may weaken our finding is the cut-off point that we used to categorize the beneficiary effect of physical activity. The recommended cut-off point for achieving effective health benefit is 450 to 750 while we just used 450. Though this made us more conservative, it may cause misclassification and dilute our magnitude of association toward a not beneficiary effects for categories of the factors that tends to achieve scores of close to cut off point.

In conclusion, Our findings indicate that achieving beneficiary effect of physical activity is highly depended on soci-demographic factors and the fact that public health interventions program need to consider these factors when planning community intervention to promote a physically active lifestyle.

\section{References}

1. Murray CJ, Lopez AD. Mortality by cause for eight regions of the world: Global Burden of Disease Study. Lancet (London, England). 1997;349(9061):1269-76.

2. Sundquist K, Qvist J, Johansson SE, Sundquist J. The longterm effect of physical activity on incidence of coronary heart disease: a 12-year follow-up study. Preventive medicine. 2005;41(1):219-25.

3. Pereira MA, Folsom AR, McGovern PG, Carpenter M, Arnett DK, Liao D, et al. Physical activity and incident hypertension in black and white adults: the Atherosclerosis Risk in Communities Study. Preventive medicine. 1999;28(3):30412.

4. Wendel-Vos GC, Schuit AJ, Feskens EJ, Boshuizen HC, Verschuren WM, Saris WH, et al. Physical activity and 
stroke. A meta-analysis of observational data. International journal of epidemiology. 2004;33(4):787-98.

5. Hu FB, Sigal RJ, Rich-Edwards JW, Colditz GA, Solomon CG, Willett WC, et al. Walking compared with vigorous physical activity and risk of type 2 diabetes in women: a prospective study. Jama. 1999;282(15):1433-9.

6. Meisinger C, Lowel H, Thorand B, Doring A. Leisure time physical activity and the risk of type 2 diabetes in men and women from the general population. The MONICA/KORA Augsburg Cohort Study. Diabetologia. 2005;48(1):27-34.

7. Slattery ML, Edwards S, Curtin K, Ma K, Edwards R, Holubkov R, et al. Physical activity and colorectal cancer. American journal of epidemiology. 2003;158(3):214-24.

8. Lagerros YT, Hsieh SF, Hsieh CC. Physical activity in adolescence and young adulthood and breast cancer risk: a quantitative review. European journal of cancer prevention : the official journal of the European Cancer Prevention Organisation (ECP). 2004;13(1):5-12.

9. Kemmler W, von Stengel S, Weineck J, Lauber D, Kalender W, Engelke K. Exercise effects on menopausal risk factors of early postmenopausal women: 3-yr Erlangen fitness osteoporosis prevention study results. Medicine and science in sports and exercise. 2005;37(2):194-203.

10. Hill JO, Wyatt HR. Role of physical activity in preventing and treating obesity. Journal of applied physiology (Bethesda, Md : 1985). 2005;99(2):765-70.

11. Littman AJ, Kristal AR, White E. Effects of physical activity intensity, frequency, and activity type on 10-y weight change in middle-aged men and women. International journal of obesity (2005). 2005;29(5):524-33.

12. Andersen LB, Schnohr P, Schroll M, Hein HO. All-cause mortality associated with physical activity during leisure time, work, sports, and cycling to work. Archives of internal medicine. 2000;160(11):1621-8.

13. U.S. Department of Health and Human Services. Physical activity guidelines advisory committee report. Washington, DC: U.S. Department of Health and Human Services. 2008.

14. WHO. physical activity. Available at: http://www.who.int/ topics/physical activity. 2011 [

15. Rutten A ZH, Schena F, Stahl T, Stiggelbout M, Auweele $\mathrm{YV}$, et al. Using different physical activity measurements in eight European countries. Results of the European Physical Activity Surveillance System (EUPASS) time series survey. . Public Health Nutr 2003;6::371-6.

16. Samitz G, Egger M, Zwahlen M. Domains of physical activity and all-cause mortality: systematic review and dose-response meta-analysis of cohort studies. International journal of epidemiology. 2011;40(5):1382-400.

17. Anzuini F, Battistella A, Izzotti A. Physical activity and cancer prevention: a review of current evidence and biological mechanisms. Journal of preventive medicine and hygiene. 2011;52(4):174-80.

18. NHANES. National Health and Nutrition Examination Survey. Available at: http://www.cdc.gov/nchs/nhanes. htm. 2012. [

19. Ainsworth BE, Haskell WL, Whitt MC, Irwin ML, Swartz AM, Strath SJ, et al. Compendium of physical activities: an update of activity codes and MET intensities. Medicine and science in sports and exercise. 2000;32(9 Suppl):S498-504.

20. Haskell WL, Lee IM, Pate RR, Powell KE, Blair SN, Franklin BA, et al. Physical activity and public health: updated recommendation for adults from the American College of Sports Medicine and the American Heart Association. Circulation. 2007;116(9):1081-93.

21. Jurakić D PZ, Anderijasevic M. Physical Activity of Croatian Population: Cross-sectional Study Using International
Physical Activity Questionnaire. . BMC public health. 2009;;50::165-73.

22. Zanchetta LM, Barros MB, Cesar CL, Carandina L, Goldbaum M, Alves MC. [Physical inactivity and associated factors in adults, Sao Paulo, Brazil]. Revista brasileira de epidemiologia $=$ Brazilian journal of epidemiology. 2010;13(3):387-99.

23. Bicalho PG HP, Gazzinelli A, Knuth AG, VelasquezMelendez G. . Adult physical activity levels and associated factors in rural communities of Minas Gerais State, Brazil. Rev Saude Publica 2010;;44((5):):884-93.

24. Carver A TA, Hesketh KD, Ridgers ND, Salmon JL, Crawford DA. . How is active transport associated with children's and adolescents' physical activity over time? . How is active transport associated with children's and adolescents' physical activity over time? . 2011;;8::126.

25. Hartman SJ, Dunsiger SI, Pekmezi DW, Barbera B, Neighbors CJ, Marquez B, et al. Impact of Baseline BMI upon the Success of Latina Participants Enrolled in a 6-Month Physical Activity Intervention. Journal of obesity. 2011;2011:921916.

26. Godin G, Belanger-Gravel A, Nolin B. Mechanism by which BMI influences leisure-time physical activity behavior. Obesity (Silver Spring, Md). 2008;16(6):1314-7.

27. Dias-da-Costa JS, Hallal PC, Wells JC, Daltoe T, Fuchs SC, Menezes AM, et al. Epidemiology of leisure-time physical activity: a population-based study in southern Brazil. Cadernos de saude publica. 2005;21(1):275-82.

28. Monteiro CA, Conde WL, Matsudo SM, Matsudo VR, Bonsenor IM, Lotufo PA. A descriptive epidemiology of leisure-time physical activity in Brazil, 1996-1997. Revista panamericana de salud publica $=$ Pan American journal of public health. 2003;14(4):246-54.

29. Visscher TL, Viet AL, Kroesbergen IH, Seidell JC. Underreporting of BMI in adults and its effect on obesity prevalence estimations in the period 1998 to 2001. Obesity (Silver Spring, Md). 2006;14(11):2054-63.

30. Pettee KK, Brach JS, Kriska AM, Boudreau R, Richardson $\mathrm{CR}$, Colbert LH, et al. Influence of marital status on physical activity levels among older adults. Medicine and science in sports and exercise. 2006;38(3):541-6.

31. He XZ, Baker DW. Differences in leisure-time, household, and work-related physical activity by race, ethnicity, and education. Journal of general internal medicine. 2005;20(3):259-66.

32. Khaw KT JR, Bingham S, Welch A, Luben R, Day N, et al. Work and leisure time physical activity assessed using a simple, pragmatic, validated questionnaire and incident cardiovascular disease and all-cause mortality in men and women: The European Prospective Investigation into Cancer in Norfolk prospective pop. Int J Epidemiol 2006;;35: :1034-43.

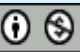

This work is licensed under a Creative Commons AttributionNon Commercial 4.0 International License. 